\title{
Plasticity versus repeatability in seabird migratory behaviour
}

\author{
Petra Quillfeldt • Christian C. Voigt • Juan F. Masello
}

Received: 28 July 2009 /Revised: 9 February 2010 /Accepted: 10 February 2010 / Published online: 9 March 2010

(C) The Author(s) 2010. This article is published with open access at Springerlink.com

\begin{abstract}
Pelagic seabird populations can use several discrete wintering areas, but it is unknown if individuals use the same wintering area year after year. This would have consequences for their population genetic structure and conservation. We here study the faithfulness of individuals to a moulting area within and among years in a small pelagic seabird, the Thin-billed prion, which moult their primary feathers during the early part of the non-breeding period. According to stable carbon isotope ratios $\left(\delta^{13} \mathrm{C}\right)$ of these feathers, $90 \%$ of Thin-billed prions moult in Antarctic and 10\% in South American waters. Repeated samples from individuals in 2 or 3 years indicated that several birds changed between Antarctic and South American moulting areas or vice versa. However, individuals moulting in an area in one year were more likely to do so again. Four out of five adults maintained highly conserved $\delta^{13} \mathrm{C}$ over the extended moulting period. One bird, however, had systematic changes in $\delta^{13} \mathrm{C}$ indicating latitudinal movements between the two areas during moult. Thus, the present data show that this seabird species has a highly flexible migratory strategy, not only at the population level, but also at the individual level, enabling these seabirds to exploit a highly unpredictable environment.
\end{abstract}

Communicated by W. Wiltschko.

P. Quillfeldt $(\bowtie) \cdot$ J. F. Masello

Max-Planck-Institut für Ornithologie,

Vogelwarte Radolfzell, Schlossallee 2,

78315 Radolfzell, Germany

e-mail: petra.quillfeldt@gmx.de

C. C. Voigt

Evolutionary Ecology Research Group,

Leibniz Institute for Zoo and Wildlife Research,

Berlin, Germany
Keywords Microevolution · Migration ·

Pachyptila belcheri . Procellariiformes $\cdot$ Seabirds .

Stable isotope analysis

\section{Introduction}

Seabird migration has not received as much attention as that of other avian groups such as passerines or waders. Although there are a few well-known examples of highly pelagic seabirds, and some of the longest migrations are known from seabirds (e.g., 64,000 km in Sooty shearwaters Puffinus griseus: Spear and Ainley 1999; Shaffer et al. 2006), the scarcity of ring recoveries and resightings has previously hindered progress in our knowledge on the atsea distribution, especially of small seabird species. Recently, methodological advances have opened up several ways forward. Geolocation devices can now be used to follow medium-sized (e.g., $500 \mathrm{~g}$ Streaked shearwater Calonectris leucomelas: Takahashi et al. 2008; $400 \mathrm{~g}$ Manx shearwater Puffinus puffinus: Guilford et al. 2009) and even small birds (e.g., Stutchbury et al. 2009) over long periods, and stable isotope analysis is increasingly used to track migration across areas with a gradient in stable isotope distribution (e.g., Hobson and Wassernaar 2008; Furness et al. 2006). The Southern Ocean is such an area, as there is a strong decline in the abundance of ${ }^{13} \mathrm{C}$ in relation to ${ }^{12} \mathrm{C}-$ depicted as $\delta^{13} \mathrm{C}$ when set in relation to an international standard-between 40 and $80^{\circ} \mathrm{S}$ latitude (Rau et al. 1991; Quillfeldt et al. 2005, 2008; Cherel and Hobson 2007; Phillips et al. 2009).

Thin-billed prions are highly pelagic seabirds, and stable isotope data showed high flexibility in their foraging distribution both during the breeding season and during migration (Quillfeldt et al. 2008). This bird uses Antarctic 
waters regularly, but not exclusively, during both the breeding and interbreeding season. For the interbreeding season, we found a bimodal distribution of $\delta^{13} \mathrm{C}$ in feathers grown during the moulting period, which suggested that most individuals migrated south to Antarctic waters (Quillfeldt et al. 2008). However, 10\% of adults migrated north, which is consistent with regular winter observations of this species off Patagonia and southern Brazil. However, it is not known whether individual Thin-billed prions are faithful to their moulting areas (polar or subtropical) within and between breeding seasons. If the population contains distinct northern and southern migrants, this would have important implications on the population structure. Therefore, we ask in the present study

1. whether individuals move between northern and southern foraging areas within a season;

2. whether two contrasting migratory strategies are found within the same population, i.e., individuals moulting consistently either in northern or southern areas;

3. and, in case individuals are not specialised to specific directions, whether the proportion of birds migrating north varies between seasons?

\section{Materials and methods}

Study site and study species

The study was carried out at the New Island Nature Reserve, Falkland Islands $\left(51^{\circ} 43^{\prime} \mathrm{S}, 61^{\circ} 17^{\prime} \mathrm{W}\right)$ during four breeding seasons 2004-2005 to 2007-2008. Thin-billed Prions are small nocturnal petrels, breeding mainly on the Falkland, Crozet and Kerguelen Islands. New Island, in the Falkland Islands, is the most important known breeding site for Thin-billed Prions with an estimated 2 million breeding pairs. The life cycle and basic biology of Thin-billed Prions have been described by Strange (1980). More recently, the feeding ecology of Thin-billed Prions was analysed using conventional diet analyses and stable isotope analyses (Cherel et al. 2002; Quillfeldt et al. 2008). Diet samples collected in February 2006 (Quillfeldt et al. 2008) were in agreement with previous studies (Strange 1980; Thompson 1989; Bocher et al. 2001; Cherel et al. 2002), suggesting that these birds feed predominantly on pelagic crustaceans (in order of importance: Themisto gaudichaudii, Euphausia vallentini, Munida gregaria, Calanus simillimus, larvae of Cirripedia) and minor amounts of cephalopod tissue.

Prions Pachyptila spp. range over wide areas of ocean and are difficult to distinguish in flight, which makes direct observations of their species' distributions nearly impossible. Information based on direct observations of Thin-billed prions is therefore limited to general descriptions such as 'disperses widely over Southern Ocean after breeding' (Carboneras 1992) and observations such as 'birds from the Falklands apparently move W, gathering in large flocks off W South America' (Carboneras 1992). This information is neither consistent with regular observations of wintering flocks off the coast of Brazil (e.g., Neves et al. 2006) nor with stable isotope data suggesting that Thin-billed prions moult predominantly in Antarctic waters (Cherel et al. 2002, 2006; Quillfeldt et al. 2008).

Sample collection

Adults were captured by hand in their nest chambers. These were reached via short access tunnels in the roof of each burrow, capped with removable stone lids. This system facilitated rapid access, reducing overall disturbance. Adults were removed from the nest and ringed with steel rings at first capture. Tail feathers (rectrices, undertail coverts or upper tail coverts) collected by gentle pulling were placed in individual plastic bags. Molecular sexing was carried out from blood samples or feathers as described in Quillfeldt et al. (2007). In analyses of subsequent years, the feather type collected and analysed was changed to avoid observer influences due to induced moult.

In 2007-2008, we collected wings of five adults found killed by Falkland skuas Catharacta antarctica or striated caracaras Phalcoboenus australis in the colony and grown in the interbreeding season, i.e., southern autumn to early winter 2007. These were used for an analysis of movements within seasons. If birds carry out large-scale movements over the moulting period, this would lead to gradual differences in carbon stable isotope ratios of successively grown feathers (e.g., Furness et al. 2006). Moult occurs outside of the breeding season (Strange 1980), and primaries are moulted sequentially and descending, starting at P1 and proceeding to P10 (Bridge 2006). Descending primary moult takes 2 to 4 months in prion species (Bridge 2006). Chicks of Thin-billed prions do not fledge until March, such that the primaries most likely represent the late autumn and early winter period (April-June).

To study individual differences in migration, we included samples of the tips of the primaries P1 to P10, marked P1a to P10a (Fig. 1). To cover a longer time, we further included the more proximal feather regions of the outermost, last grown feather $(\mathrm{P} 10 \mathrm{~b}-\mathrm{f})$.

Stable isotope analysis

Stable isotope analysis of feathers of the years 2004-2005 to 2007-2008 were carried out at the Leibniz Institute for Zoo and Wildlife Research, Berlin, Germany.

Small fragments of the feathers were cut from the feather tip (P1a, P2a, etc.) or more proximal feather regions (P10b-f) 


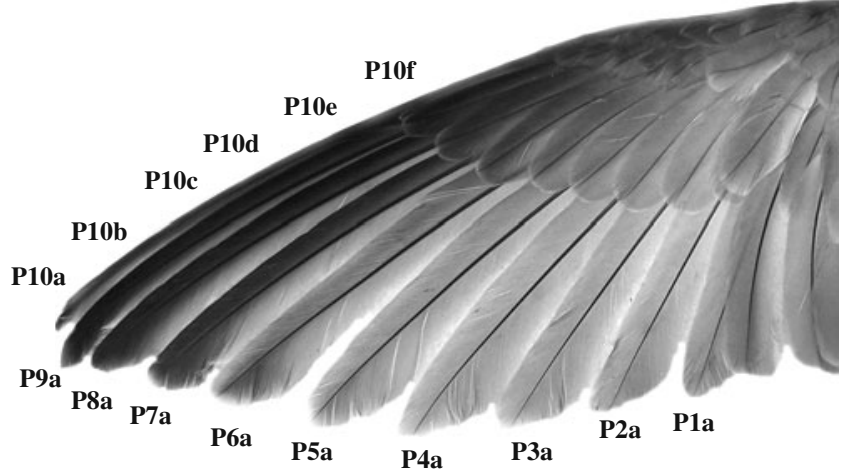

Fig. 1 Wing of a Thin-billed prion prior to sample taking, showing the primaries and sample points

using stainless steel scissors. Stable carbon and nitrogen isotope analyses were carried out on $0.35 \mathrm{mg}$ aliquots, weighed into tin cups. We selected feathers free from any obvious contamination. Studies have shown that carbon means did not shift when feathers were cleaned, supporting the notion that carbon stable isotope ratios are robust to minor contamination (Mizutani et al. 1992; Paritte and Kelly 2009). As cleaning agents may remove contaminants but may also change feather isotope values, either by leaving a residue with a different enough stable isotope ratio to change the measured value or by causing atom exchange (e.g., Paritte and Kelly 2009), we decided not to apply a cleaning protocol.

Carbon and nitrogen isotope ratios were measured simultaneously by continuous-flow isotope ratio mass spectrometry using a Flash Elemental Analyser (Thermo Finnigan, Bremen, Germany) linked to a Delta V Advantage Isotope Ratio Mass Spectrometer (Thermo Finnigan, Bremen, Germany). Two laboratory standards were analysed for every ten unknown samples, allowing any instrument drift over a typical 14-h run to be corrected. Stable isotope ratios were expressed in $\delta$ notation as parts per thousand (\%) deviation from the international standards V-Pee dee belemnite (carbon) and AIR (nitrogen), according to the following equation $\delta X=\left[\left(R_{\text {sample }} / R_{\text {standard }}\right)-1\right] \times 1000$ where $X$ is ${ }^{15} \mathrm{~N}$ or ${ }^{13} \mathrm{C}$ and $R$ is the corresponding ratio ${ }^{15} \mathrm{~N} /{ }^{14} \mathrm{~N}$ or ${ }^{13} \mathrm{C} /{ }^{12} \mathrm{C}$. Based on internal standards ( $N=165$, tyrosin; Roth, Germany), the analytical precision $( \pm 1$ SD) equalled $\pm 0.16 \%$ and $\pm 0.29 \%$ for $\delta{ }^{15} \mathrm{~N}$ and $\delta^{13} \mathrm{C}$, respectively.

Additionally, feathers of the years 2004-2005 and 20052006 analysed at the NERC stable isotope facility at SUERC Glasgow as described previously (Quillfeldt et al. 2008) were included in the dataset.

Data analysis

Data analysis was carried out using SigmaStat 2.03 and SPSS 11.0. We checked for deviations from normality with Kolmogorov-Smirnov tests. Homogeneity of error varian- ces was checked by plotting residuals against predicted values. Stable isotope ratios of feathers from adult birds did not have equal variances, while population data were not normally distributed. We thus used nonparametric tests throughout. Significance was assumed at $\alpha<0.05$, and means are given with standard errors.

The cut-off point between 'northern' and 'southern' moulting birds was defined as $\delta^{13} \mathrm{C}=-21 \%$. This was based on a frequency distribution of observed $\delta^{13} \mathrm{C}$ values, which had a large peak at $-25 \%$, a smaller peak at $-19 \%$, and a minimum at $-21 \%$ (Fig. 2). Values $<-23 \%$ indicate highAntarctic waters, thus the large peak at $-25 \%$ corresponding to Antarctic moulting grounds (e.g., Quillfeldt et al. 2008). As there is very little longitudinal variation in POM isoscapes within high-Antarctic waters, the 'southern' moulting birds can potentially forage in a large area around Antarctica at the same latitudes. The more northern $\delta^{13} \mathrm{C}$ values peaking at $-19 \%$ corresponded to more northern moulting grounds, although exact locations are almost impossible to locate because of the lack of appropriate isoscapes and isotope gradients at latitudes north of $40^{\circ} \mathrm{S}$ (e.g., Quillfeldt et al. 2005).

For the comparison between years and sexes, we used independent samples by including each bird only at first capture.

\section{Results}

Movements within a year

Individuals were remarkably constant in their $\delta^{13} \mathrm{C}$ values across the primaries P1a to P10a. All five individuals differed in their $\delta^{13} \mathrm{C}$ (Fig. 3, Friedman repeated measures

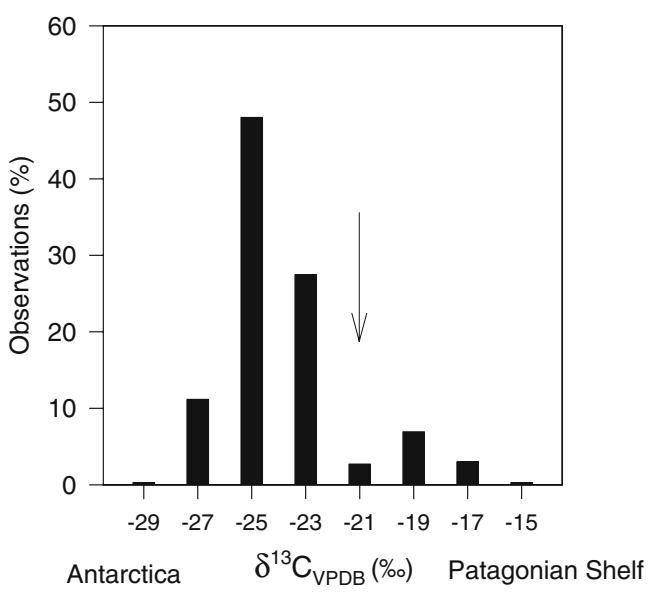

Fig. 2 Bimodal distribution of $\delta^{13} \mathrm{C}$ values of feathers of Thin-billed prions showing the cut-off point at $-21 \%$, marked with an arrow. Samples of all years were included, with repeated samples of individuals excluded 


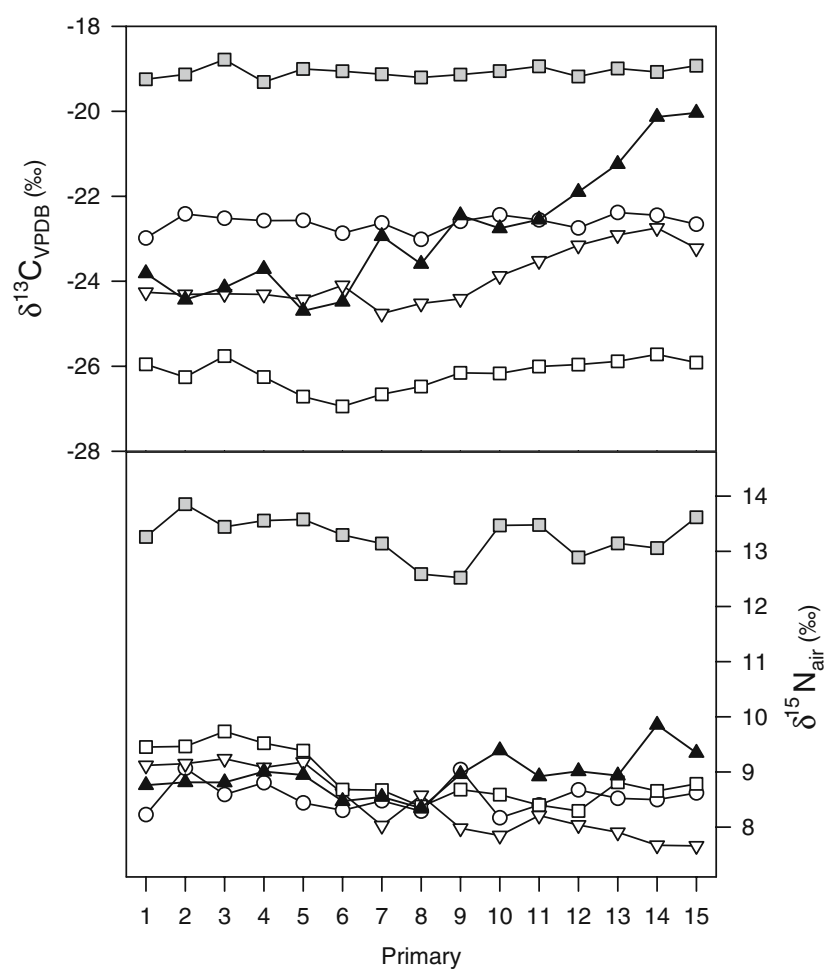

Fig. 3 Within-winter consistency of stable isotope ratios in primaries of five Thin-billed prions. Three individuals moulted exclusively in the southern area (white symbols) and one in the north (grey symbols). The fifth bird (black symbols) moved north during the later part of the moult, indicated by gradually increasing $\delta^{13} \mathrm{C}$ values

ANOVA on ranks, $\chi^{2}=37.4, d f 4, p<0.001$, Tukey post-hoc test determined each bird as a homogenous subset). Three individuals moulted exclusively in the southern area (Fig. 3, white symbols) and one in the north (Fig. 3, grey symbols). In the fifth bird (Fig. 3, black symbols), the inner primaries $\mathrm{P} 1-\mathrm{P} 6$ had lower $\delta^{13} \mathrm{C}$ than the outer primaries, especially the last grown proximal parts of the outer primary P10. This strongly suggests that this bird moved north during the later part of the moult, even crossing the cut-off point between 'northern' and 'southern' moulting areas at $-21 \%$. However, the $\delta^{15} \mathrm{~N}$ values of this bird (Fig. 3, black symbols) remained much lower than that of the bird that stayed in the north (Fig. 3, grey symbols).

Individuals also differed in $\delta^{15} \mathrm{~N}$ values across the primaries P1a to P10a $\left(\chi^{2}=28.2\right.$, $\left.d f 4, p<0.001\right)$, but this was due to the high values of the northerly moulting individual (Tukey post-hoc test determined this bird as homogenous subset).

Migration strategies on the individual level

Of 81 adults sampled in two seasons, 68 (84\%) had isotope signatures typical for southern moulting habitats in both years, ten $(12 \%)$ had spent one moulting period south and one north, and three (4\%) went north in both years. The observed values for moving into the same direction again year after year were larger than expected (Fig. 4, Fisher's exact test, $p=0.027$ ).

Of 21 adults sampled in three seasons, $16(76.2 \%)$ had southern isotope signatures in all 3 years, four $(19.0 \%)$ had spent two moulting periods south and one north and one $(4.8 \%)$ went north for two seasons. None of the birds went north for all three moulting periods, indicating that the population does not contain 'northern specialists'.

Migration strategies on the population level

The proportion of birds migrating north equalled 10.9\% (36 of 331 birds). This ratio did not differ among the sexes $\left(\chi^{2}=\right.$ 0.004 , df $1, p=0.952,10.6 \%$ of 151 males migrated north, compared to $10.1 \%$ of 139 females). The proportion of birds migrating north did not differ among years $\left(\chi^{2}=3.0, d f 3, p=\right.$ 0.392 ), being $8.4 \%$ (seven of 83 adults) in feathers collected in 2005, 6.9\% in $2006(n=29), 14.3 \%$ in $2007(n=140)$ and $8.9 \%$ in $2008(n=79)$. The power of the performed test (0.264) was below the desired power of 0.80 .

The feathers collected in different years varied in their $\delta^{13} \mathrm{C}$ and $\delta^{15} \mathrm{~N}$ values (Table 1, Fig. 5, see legend for statistical details), especially the year 2008 was characterised by low $\delta^{13} \mathrm{C}$ and high $\delta^{15} \mathrm{~N}$ values. This was not caused by a potential bias from data collected from birds with northward migratory route, as the statistical results, including the homogenous subsets determined by the posthoc tests, remained unchanged after removing the northern birds from the dataset.

\section{Discussion}

The present data demonstrate a high plasticity in migratory behaviour of a small seabird: In general, Thin-billed prions

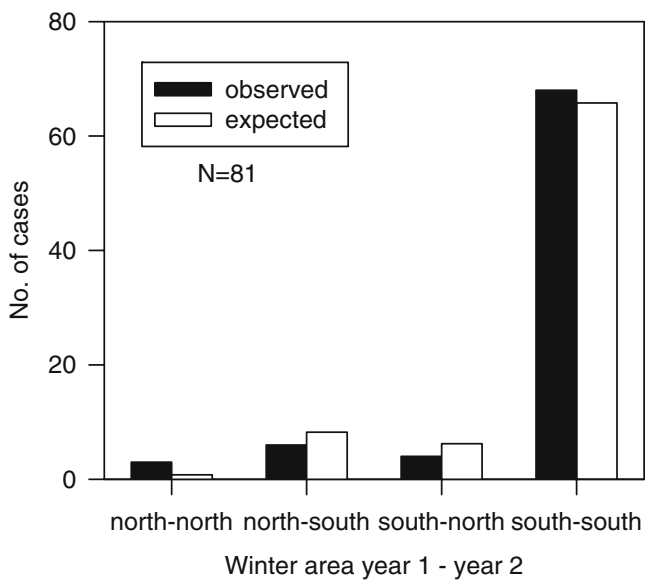

Fig. 4 Comparison of observed and expected frequencies of migration areas in 81 Thin-billed prions sampled over 2 years, according to stable isotope signatures in tail feathers 
Table 1 Stable carbon and nitrogen isotope ratios in tail feathers of adult Thin-billed prions sampled over 4 years

\begin{tabular}{|c|c|c|c|c|c|c|c|c|c|}
\hline \multirow[t]{2}{*}{ Year } & \multirow[t]{2}{*}{$N$} & \multicolumn{4}{|c|}{$\delta^{13} \mathrm{C}(\%)$} & \multicolumn{4}{|c|}{$\delta^{15} \mathrm{~N}(\% 0)$} \\
\hline & & Mean & SD & Min & Max & Mean & SD & Min & Max \\
\hline 2005 & 83 & -24.2 & 2.1 & -26.1 & -14.7 & 8.9 & 2.1 & 7.1 & 17.0 \\
\hline 2006 & 29 & -24.9 & 2.4 & -28.1 & -18.3 & 8.5 & 2.2 & 6.5 & 16.7 \\
\hline 2007 & 140 & -23.1 & 2.1 & -26.4 & -16.9 & 9.9 & 2.3 & 7.1 & 16.3 \\
\hline 2008 & 79 & -24.0 & 2.1 & -27.6 & -16.6 & 9.2 & 1.6 & 7.1 & 16.5 \\
\hline
\end{tabular}

move south for the moulting period and stay there, except for a few individuals, but individuals may change their migratory direction again in the next year. These findings shed new light on migratory strategies of seabirds.

Some seabird species are sedentary, while others migrate over extreme distances. Thus far, few species have been studied in sufficient detail and number, particularly with respect to individual migration strategies. However, the few published studies suggest that a high plasticity in migratory directions, as found in the present study, is more common than previously anticipated. For example, a satellite transmitter study showed that about half of the Great Skuas Stercorarius skua from Foula, Shetland wintered over the continental shelf off Iberia and about half moved to the continental shelf off West Africa (Furness et al. 2006). In a stable isotope study of Wilson's storm-petrels Oceanites oceanicus from the South Shetlands, four of the 63 sampled birds moulted in a separate, northerly area to the remaining birds (Gladbach et al. 2007). Further, a study of Cory's shearwaters using geolocators found North Atlantic and Mediterranean birds of this species use three wintering areas, associated with upwelling systems of the tropical and south Atlantic (Gonzáles-Solís et al. 2007). Similarly, Sooty shearwaters breeding in New Zealand travelled across the equator to the North Pacific to three discrete regions off Japan, Alaska or California (Shaffer et al. 2006), and Northern Gannets Morus bassanus used four different wintering areas (Kubetzki et al. 2009)

However, in these four examples the general direction of the migration is constant, while only the distance travelled or the final wintering area differed. Also, the examples above follow the most common pattern of equatorward or trans-equatorial migration. In contrast, Thin-billed prions are unusual as they may move in contrary directions, polewards or equatorwards from their breeding site. While most Thin-billed prions from the Falkland Islands spend the moulting period in Antarctic waters, about $10 \%$ of adults spent the interbreeding period in a more northern foraging area according to a
Fig. 5 Stable carbon and nitrogen isotope ratios in tail feathers of adult Thin-billed prions sampled over 4 years. Boxplots show medians, fifth and 95 th percentiles, and outliers. The birds differed among years in both their $\delta^{13} \mathrm{C}$ values (ANOVA on Ranks, $H=73.8$, df $3, p<0.001)$ and $\delta^{15} \mathrm{~N}$ values $(H=73.8$, df $3, p<0.001)$.

Letters over the boxes indicate homogenous subsets determined by post-hoc tests (Dunn's method)

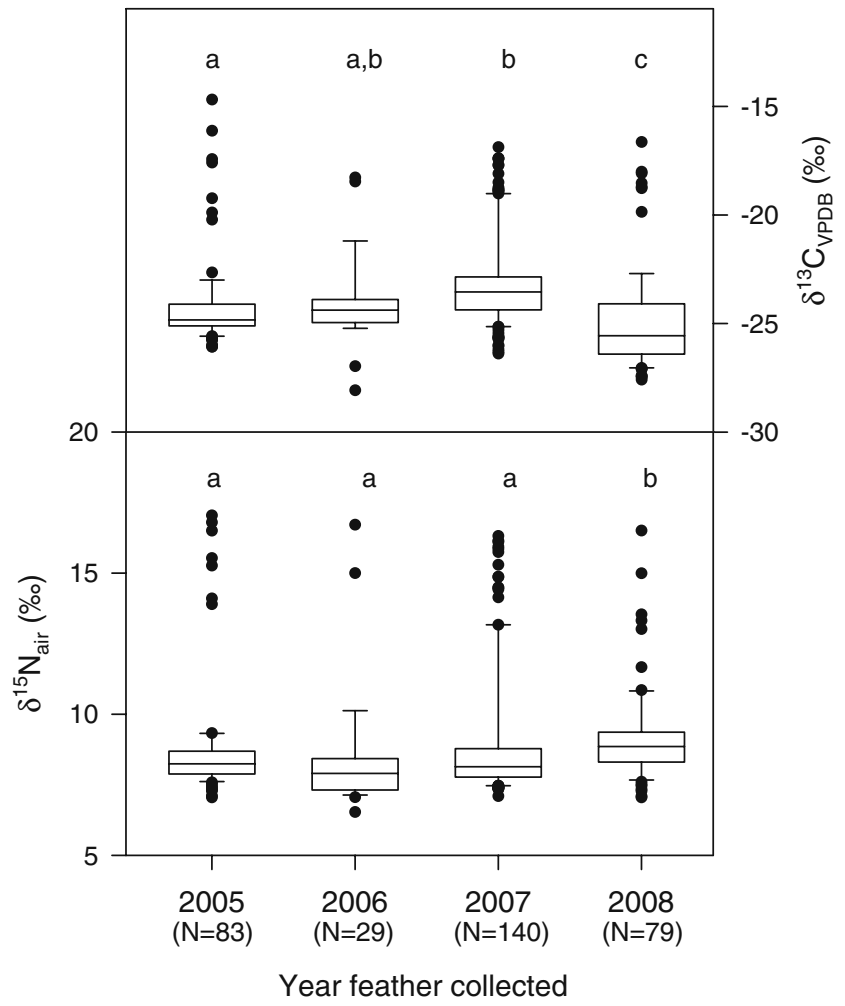


smaller sample of feathers (Quillfeldt et al. 2008). We here analysed a larger sample size and number of years and included repeated samples for known (ringed) individuals in two or three moulting periods.

With the larger sample size, we found a consistent pattern of $10.9 \%$ of birds migrating north, with no major inter-year variations. The relatively minor changes in carbon signatures among years (Fig. 5) might be due to baseline changes in the isotopic signatures or to changes in the movements of the birds. To the best of our knowledge, there are no rigorous studies showing the accuracy and consistency of the geographic gradients in carbon signatures over the years.

Do individuals move between northern and southern foraging areas within a moulting season?

Of five individuals, we analysed series of primary feathers, covering an estimated 3 to 4 months of the autumn to early winter period. Four birds, one in the north and three in the south, maintained constant $\delta^{13} \mathrm{C}$ and $\delta^{15} \mathrm{~N}$ values very constant over the moult period, indicating no major latitudinal movements.

A single bird showed a systematic change in its $\delta^{13} \mathrm{C}$ and to a lesser extent, $\delta^{15} \mathrm{~N}$ values. This indicated that after starting moult in Antarctic waters, the bird moved north during the moulting period. As the tail feathers are moulted towards the end of the wing moult, using tail feathers for the analysis would increase the likelihood to classify such a far-ranging bird as 'northern migrant'. To take such movements into account, future studies from live birds might sample a piece of an inner primary (P1 or P2), representing the autumn to early winter, and a piece of a tail feather representing a later winter period. As whole wings were collected from birds found dead, we did not know the exact status (immatures vs. adults breeders, non-breeders or failed breeders) of the five individuals. In several seabird species, immature birds are known to wander more extensively than successful breeders. Thus, the prion exhibiting a progressive shift in its moulting area might have been an immature bird.

However, it seems clear from the present results that in most cases, the non-breeding movements of Thin-billed prions can be divided into a phase of large-scale migration and small-scale movements within a well-defined moulting area, where they remain during the whole moult. Thus, movements within the moulting period alone do not explain the observed bidirectional pattern of migration. A similar pattern has been found in Cory's shearwaters (GonzálesSolís et al. 2007) and Sooty shearwaters (Shaffer et al. 2006), where individuals migrated rapidly to one of three main wintering grounds and remained there until their homeward migration.
Are individuals faithful to their moulting area among years?

Fidelity to wintering areas (also termed 'winter philopatry', e. g., Robertson and Cooke 1999) and to intermediate staging sites is well documented for many bird species (e.g., waterfowl: Iverson et al. 2004; Guillemain et al. 2009, waders: Gunnarsson et al. 2004, passeriformes: Koronkiewicz et al. 2006). However, winter philopatry is not universal (Robertson and Cooke 1999; Mehl et al. 2004), and thus, it cannot be assumed that migration strategies are necessarily fixed from 1 year to the next (Phillips et al. 2005).

Wintering site philopatry has previously been observed in two albatross species (Phillips et al. 2005; Croxall et al. 2005). By using stable isotopes, we, here, were able to study whether a small marine bird repeatedly uses the same wintering area year after year. According to Berthold (1996), an inherited endogenous time and direction programme controls migratory traits, which is subject to selection and rapid adaptation through microevolution. Following this line of argument, we expected the direction of birds to be endogenously determined and thus, constant over the years.

Repeated samples for known (ringed) individuals in two or three moulting periods provided evidence against the hypothesis that there are two strategies within the same population, i.e., individuals moulting consistently either in northern or southern areas. Of 21 adults sampled in three seasons, no birds went north for all three winters, indicating that the population does not contain 'northern specialists'. Individuals can change from being southerly migrants one year to moult in South American waters in the next. However, more individuals than expected by chance showed consistent behaviour among years, thus suggesting some genetically determined predisposition, as found in other birds (e.g., Pulido et al. 1996).

How do Thin-billed prions decide where to migrate? The mechanisms might be similar to the threshold model (Berthold et al. 1990; Pulido et al. 1996) described in partially migratory songbirds, i.e., populations that are composed of individuals that migrate and individuals that remain resident. There, individuals can change from being migrants one year to becoming residents the next (e.g., Able and Belthoff 1998), which is somewhat similar to our findings, although we do not exactly know the location and extent of movement of the northern moulting Thin-billed prions. Whether an individual migrates or not is determined by a threshold that may not be fixed but influenced both genetically and environmentally (Pulido et al. 1996). Genetically, animals differ in their individual disposition for migration, while external factors such as population density and winter food sources (Nilsson et al. 2006) may influence in addition whether or in what direction a bird migrates. According to the threshold model, all birds have 
migratory activity, although in residents this is below a limit of expression or detection. The proportion of individuals that express migration in a population can range from close to 0 for fully resident species to close to 1 for fully migratory species or populations (Berthold et al. 1990; Pulido et al. 1996; Berthold 1999). Thin-billed prions would be classified as fully migratory as they disappear from the breeding colonies. However, their moulting areas, especially for the northern migrants, may overlap with their foraging areas in the breeding season. If this was the case, then northern migrants might be classified 'residents' and the decision to migrate either north or south might depend largely on individual migratory activity and to a lesser degree on external factors, as in most partial migrants.

In the present study, the proportion of birds migrating north ranged between $7 \%$ and $14 \%$, but our sample size did not allow us to determine whether there were significant differences between years. In the year 2008, the birds had lower $\delta^{13} \mathrm{C}$ and higher $\delta^{15} \mathrm{~N}$ values even within the southern area, suggesting that the moulting area was less productive (lower $\delta^{13} \mathrm{C}$, see e.g., Fry and Wainright 1991) or birds took different zooplankton (higher $\delta^{15} \mathrm{~N}$ ) than in the other years. However, the proportion of birds using this area in 2008 was not different from average. Thus, at present we have little evidence that the birds adjust their migratory strategy to environmental conditions in either their northern or southern moulting area. To determine the wintering areas and possible winter food sources, future stable isotope studies should be combined with tracking studies using geolocators. This basic information will then enable us to look for the factors determining how individuals use wintering areas according to external factors and individual disposition.

In conclusion, the present data show for the first time that migratory behaviour in a marine bird species is highly flexible. The birds have a tendency to use a specific moult area, suggesting potential for microevolution of migratory behaviour. However, individuals are not restricted to one area or migratory direction and can change moulting period areas within and between seasons. Such high flexibility is most likely advantageous, as it enables Thin-billed prions to exploit a highly unpredictable environment.

\footnotetext{
Acknowledgements We are grateful to the New Island Conservation Trust for permission to work on the island and for providing accommodation and transport. We would like to thank Ian, Maria and Georgina Strange and Dan Birch for their contributions, the logistics at New Island. Karin Sörgel carried out the sample preparation and stable isotope analysis at IZW. Riek van Noordwijk carried out molecular sex determination. Institut für Vogelforschung Wilhelmshaven, Germany, provided steel rings to mark individuals. This study was funded by grants provided by DFG, Germany (Qu 148/1-ff) and NERC, UK (Grant-in-Kind EK 82-08/05) and approved by the Falkland Islands Government (Environmental Planning Office). The manuscript benefited from the constructive comments of two anonymous referees.
}

Ethical standards The field protocols complied with the laws and were approved by the Falkland Islands Government (Environmental Planning Office).

Conflict of interest The authors declare that they have no conflict of interest.

Open Access This article is distributed under the terms of the Creative Commons Attribution Noncommercial License which permits any noncommercial use, distribution, and reproduction in any medium, provided the original author(s) and source are credited.

\section{References}

Able KP, Belthoff JR (1998) Rapid 'evolution' of migratory behaviour in the introduced house finch of eastern North America. Proc R Soc B 265:2063-2071

Berthold P (1996) Control of bird migration. Chapman and Hall, London

Berthold P (1999) A comprehensive theory for the evolution, control and adaptability of avian migration. Ostrich 70:1-11

Berthold P, Mohr G, Querner U (1990) Steuerung und potentielle Evolutionsgeschwindigkeit des obligaten Teilzieherverhaltens: Ergebnisse eines Zweiweg-Selektionsexperiments mit der Mönchsgrasmücke (Sylvia atricapilla). J Ornithol 131:33-45

Bocher P, Cherel Y, Labat JP, Mayzaud P, Razouls S, Jouventin P (2001) Amphipod-based food web: Themisto gaudichaudii caught in nets and by seabirds in Kerguelen waters, southern Indian Ocean. Mar Ecol Prog Ser 223:261-276

Bridge ES (2006) Influences of morphology and behavior on wingmolt strategies in seabirds. Mar Orn 34:7-19

Carboneras C (1992) Order Procellariiformes. In: del Hoyo J, Elliot A, Sargatal J (eds) Handbook of the birds of the world, vol 1. Ostrich to ducks. Lynx Edicions, Barcelona, pp 198-278

Cherel Y, Hobson KA (2007) Geographical variation in carbon stable isotope signatures of marine predators: a tool to investigate their foraging areas in the Southern Ocean. Mar Ecol Prog Ser 329:281-287

Cherel Y, Bocher P, De Broyer C, Hobson KA (2002) Food and feeding ecology of the sympatric thin-billed Pachyptila belcheri and Antarctic $P$. desolata prions at Iles Kerguelen, Southern Indian Ocean. Mar Ecol Prog Ser 228:263-281

Cherel Y, Phillips RA, Hobson KA, McGill R (2006) Stable isotope evidence of diverse species-specific and individual wintering strategies in seabirds. Biol Lett 2:301-303

Croxall JP, Silk JRD, Phillips RA, Afanasyev V, Briggs DR (2005) Global circumnavigations: tracking year-round ranges of nonbreeding albatrosses. Science 307:249-250

Fry B, Wainright SC (1991) Diatom sources of ${ }^{13} \mathrm{C}$-rich carbon in marine food webs. Mar Ecol Prog Ser 76:149-157

Furness RW, Crane JE, Bearhop S, Garthe S, Käkelä A, Käkelä R, Kelly A, Kubetzki U, Votier SC, Waldron S (2006) Techniques to link individual migration patterns of seabirds with diet specialization, condition and breeding performance. Ardea 94:631-638

Gladbach A, McGill RAR, Quillfeldt P (2007) Foraging areas of Wilson's storm-petrel Oceanites oceanicus in the breeding and inter-breeding period determined by stable isotope analysis. Polar Biol 30:1005-1012

Gonzáles-Solís J, Croxall JP, Oro D, Ruiz X (2007) Trans-equatorial migration and mixing in the wintering areas of a pelagic seabird. Front Ecol Environ 5:297-301

Guilford T, Meade J, Willis J, Phillips RA, Boyle D, Roberts S, Collett M, Freeman R, Perrins CM (2009) Migration and stopover in a 
small pelagic seabird, the Manx Shearwater Puffinus puffinus: insights from machine learning. Proc R Soc B 276:1215-1223

Guillemain M, Fuster J, Lepley M, Mourovanval J-B, Massez G (2009) Winter site fidelity is higher than expected for Eurasian Teal Anas crecca in the Camargue, France. Bird Study 56:272-275

Gunnarsson TG, Gill JA, Sigurbjornsson T, Sutherland WJ (2004) Pair bonds-arrival synchrony in migratory birds. Nature 431:646

Hobson KA, Wassernaar LI (2008) Tracking animal migration with stable isotopes. Academic Press, Amsterdam

Iverson SA, Esler D, Rizzolo DJ (2004) Winter philopatry of harlequin ducks in Prince William Sound, Alaska. Condor 106:711-715

Koronkiewicz TJ, Sogge MK, Van Riper C III, Paxton EH (2006) Territoriality, site fidelity, and survivorship of Willow Flycatchers wintering in Costa Rica. Condor 108:558-570

Kubetzki U, Garthe S, Fifield D, Mendel B, Furness RW (2009) Individual migratory schedules and wintering areas of northern gannets. Mar Ecol Prog Ser 391:257-265

Mehl KR, Alisauskas RT, Hobson KA, Kellett DK (2004) To winter east or west? Heterogeneity in winter philopatry in a centralArctic population of king eiders. Condor 106:241-251

Mizutani H, Fukuda M, Kabaya Y (1992) C-13 enrichment and N-15 enrichment factors of feathers of 11 species of adult birds. Ecology 73:1391-1395

Neves T, Vooren CM, Bugoni L, Olmos F, Nascimento L (2006) Distribuição e abundância de aves marinhas no sudeste-sul do Brasil. In: Neves T, Bugoni L, Rossi-Wongtschowski CLB (eds) Aves oceânicas e suas interações com a pesca na região SudesteSul do Brasil. USP (Série Documentos Revizee: Score Sul), São Paulo, pp 11-35

Nilsson ALK, Linstrom A, Jonzen N, Nilsson SG, Karlsson L (2006) The effect of climate change on partial migration - the blue tit paradox. Glob Chang Biol 12:2014-2022

Paritte JM, Kelly JF (2009) Effect of cleaning regime on stableisotope ratios of feathers in Japanese quail (Coturnix japonica). Auk 126:165-174

Phillips RA, Silk JRD, Croxall JP, Afanasyev V, Bennett VJ (2005) Summer distribution and migration of nonbreeding albatrosses: individual consistencies and implications for conservation. Ecology 86:2386-2396

Phillips RA, Bearhop S, McGill RAR, Dawson DA (2009) Stable isotopes reveal individual variation in migration strategies and habitat preferences in a suite of seabirds during the nonbreeding period. Oecologia 160:795-806

Pulido F, Berthold P, van Noordwijk AJ (1996) Frequency of migrants and migratory activity are genetically correlated in a bird population: evolutionary implications. Proc Natl Acad Sci USA 93:14642-14647

Quillfeldt P, McGill RAR, Furness RW (2005) Diet and foraging areas of Southern Ocean seabirds and their prey inferred from stable isotopes: review and case study of Wilson's storm-petrel. Mar Ecol Prog Ser 295:295-304

Quillfeldt P, Strange IJ, Segelbacher G, Masello JF (2007) Male and female contributions to provisioning rates of Thin-billed prions Pachyptila belcheri in the South Atlantic. J Ornithol 148:367372

Quillfeldt P, McGill RAR, Strange IJ, Masello JF, Weiss F, Brickle P, Furness RW (2008) Stable isotope analysis reveals sexual and environmental variability and individual consistency in foraging of Thin-billed prions. Mar Ecol Prog Ser 373:137-148

Rau GH, Takahashi T, Des Marais DJ, Sullivan CW (1991) Particulate organic matter $\delta^{13} \mathrm{C}$ variations across the Drake Passage. J Geophys Res 96:15131-15135

Robertson GJ, Cooke F (1999) Winter philopatry in migratory waterfowl. Auk 116:20-34

Shaffer SA, Tremblay Y, Weimerskirch H, Scott D, Thompson DR, Sagar PM, Moller H, Taylor GA, Foley DG, Block BA, Costa DP (2006) Migratory shearwaters integrate oceanic resources across the Pacific Ocean in an endless summer. Proc Natl Acad Sci USA 103:12799-12802

Spear LB, Ainley DG (1999) Migration routes of sooty shearwaters in the Pacific Ocean. Condor 101:205-218

Strange IJ (1980) The thin-billed prion, Pachyptila belcheri, at New Island, Falkland Islands. Gerfaut 70:411-445

Stutchbury BJM, Tarof SA, Done T, Gow E, Kramer PM, Tautin J, Fox JW, Afanasyev V (2009) Tracking long-distance songbird migration by using geolocators. Science 323:896

Takahashi A, Ochi D, Watanuki Y, Deguchi T, Wilson RP, Oka N, Afanasyev V, Fox JW, Trathan PN (2008) Post-breeding movement and activities of two Streaked Shearwaters in the north-western Pacific. Ornithol Sci 7:29-35

Thompson KR (1989) An assessment of the potential for competition between seabirds and fisheries in the Falkland Islands. Falkland Islands Foundation, Brighton 